\title{
Lactate Release from the Subcutaneous Tissue in Lean and Obese Men
}

\author{
Per-Anders Jansson, Annhild Larsson, * Ulf Smith, and Peter Lönnroth \\ Departments of Internal Medicine and * Radiation Physics, University of Göteborg, Sahlgren's Hospital, S-413 45 Göteborg, Sweden
}

\begin{abstract}
Lactate concentration in the subcutaneous interstitial fluid and adipose tissue blood flow (ATBF, $\mathrm{ml} / 100 \mathrm{~g} \cdot \mathrm{min})$ were simultaneously measured with the microdialysis technique combined with ${ }^{133} \mathrm{Xe}$ clearance in the abdominal and femoral subcutaneous adipose tissue in nine lean and nine obese men. The studies were performed both in the postabsorptive state and $2 \mathrm{~h}$ after an oral glucose load and the results compared to the lactate levels in arterialized venous plasma.

After an overnight's fast, arterial lactate was $738 \pm 49$ and $894 \pm 69 \mu \mathrm{M}($ mean \pm SE) $(P<0.05)$ in the lean and obese subjects, respectively. The interstitial lactate levels were significantly higher than blood lactate in both subject groups without any regional differences. Abdominal and femoral ATBF was $3.2 \pm 0.6$ vs. $2.8 \pm 0.4$ and $1.7 \pm 0.3$ vs. $2.4 \pm 0.4 \mathrm{ml} / 100 \mathrm{~g} \cdot \min (P$ $<0.05)$ in lean and obese subjects, respectively. Mean apparent lactate release from the abdominal vs. femoral adipose tissue in the fasting state was $10.5 \pm 3.1$ vs. 8.6 \pm 2.3 and $6.0 \pm 2.3$ vs. $8.5 \pm 2.3 \mu \mathrm{mol} / \mathrm{kg} \cdot \mathrm{min}$ (NS) in lean and obese subjects, respectively. Both plasma and interstitial lactate levels increased significantly after an oral glucose load in both subject groups. However, apparent lactate release increased significantly only in the lean group.

It is concluded that subcutaneous adipose tissue is a significant source of whole-body lactate release in the postabsorptive state and that this is further enhanced in obese subjects due to their large adipose mass. (J. Clin. Invest. 1994. 93:240-246.) Key words: blood flow $\bullet$ lactate $\bullet$ microdialysis $\bullet$ subcutaneous adipose tissue ${ }^{133} \mathrm{Xe}$-clearance
\end{abstract}

\section{Introduction}

Lactate is thought to be produced mainly in skeletal muscle, the splanchnic area, erythrocytes, brain, and skin (1). However, recent evidence suggests that the adipose tissue may also be a significant source of lactate release. First, lactate is a major metabolite of glucose in adipocytes from both rats (2) and humans (3). Secondly, adipose tissue in dogs has clearly been shown to produce lactate (4). Thirdly, evidence for lactate formation by human adipose tissue in vivo was recently found by the cannulation of superficial abdominal veins ( 5 ) and by measurements in the subcutaneous interstitial fluid in two studies with the microdialysis technique $(6,7)$.

Address correspondence to Dr. Per-Anders Jansson, Department of Internal Medicine, Sahlgren's Hospital, S-413 45 Göteborg, Sweden.

Received for publication 16 February 1993 and in revised form 26 July 1993

J. Clin. Invest.

(c) The American Society for Clinical Investigation, Inc.

0021-9738/94/01/0240/07 \$2.00

Volume 93, January 1994, 240-246
Lactate is an important gluconeogenic precursor during fasting (8). Interestingly, several studies have shown that plasma lactate levels are elevated in obese subjects during fasting (9-11) and that in insulin-resistant subjects fasting lactate levels correlate positively with adipose tissue mass and negatively with insulin sensitivity (9). Also, it has been reported that postabsorptive plasma levels of lactate are further elevated in patients with non-insulin-dependent diabetes mellitus, a condition known to be associated with insulin resistance (12). Thus, indirect evidence exists to suggest that the lactate release from the adipose tissue is enhanced in the postabsorptive state in obese subjects and that this is related to insulin resistance (13).

Another implication of the finding that adipose tissue releases lactate, not only during fasting but also after a glucose load (6), is that adipose tissue may utilize more glucose in the postprandial state than originally proposed (14). However, balance studies where superficial abdominal arterial-venous concentration differences were measured could confirm that the adipose tissue only consumes a few percent of an oral glucose load (5). Surprisingly, in a microdialysis study by HagströmToft and collaborators (7) adipose tissue was found not to release lactate in the fasting state but only after an oral glucose load.

In a recent study, we combined the microdialysis technique with ${ }^{133} \mathrm{Xe}$ clearance to measure subcutaneous extracellular glycerol levels and tissue blood flow (15). This technique allowed the calculation of the subcutaneous rate of glycerol release per tissue weight (15). In the present study, the same technique was used to measure lactate release from the subcutaneous tissue in lean and obese subjects. The data show that lactate is apparently released in proportion to the adipose tissue mass during fasting, whereas lactate release after an oral glucose load is only enhanced in lean individuals.

\section{Methods}

Subjects. Nine obese and nine lean male volunteers of similar age and with a normal glucose tolerance (16) participated in the study. The clinical characteristics of the subjects are shown in Table $I$. All subjects had been weight-stable for at least 3 mo before the study and they took no regular medication. The participants were asked to maintain their regular dietary habits and physical activity. They abstained from alcohol for $3 \mathrm{~d}$ before the investigation and did not use nicotine the evening before the study. The volunteers gave their informed consent and the study was approved by the Ethical Committee and the Radiation Safety Committee of the University of Göteborg.

Study protocol. After fasting overnight, the subjects were investigated in the supine position in a room kept at $26^{\circ} \mathrm{C}$. A polyethylene catheter was placed in a dorsal hand vein. The forearm was heated with electric pads which leads to arterialization of the venous blood. Previous experiments in our laboratory have shown that the protocol used results in $\mathrm{a} \mathrm{O}_{2}$ saturation of $93 \pm 1 \%$ in venous blood (17). Control experiments showed that the pads did not alter the interstitial lactate levels nor the adipose tissue blood flow in either the abdominal or the femoral region (not shown). 
Table I. Clinical and Biochemical Characteristics of the Lean and Obese Individuals

\begin{tabular}{|c|c|c|c|c|c|c|}
\hline & Age & Body fat & BMI & WHR & Fasting glucose & Fasting lactate \\
\hline & $y r$ & $k g$ & $\mathrm{~kg} / \mathrm{m}^{2}$ & & $m M$ & $\mu M$ \\
\hline Lean & $28 \pm 1$ & $11 \pm 1$ & $22.0 \pm 0.3$ & $0.87 \pm 0.02$ & $4.8 \pm 0.1$ & $738 \pm 49$ \\
\hline Obese & $29 \pm 2$ & $48 \pm 6$ & $39.9 \pm 2.1$ & $1.07 \pm 0.01$ & $4.8 \pm 0.2$ & $894 \pm 69$ \\
\hline \multirow[t]{3}{*}{$P$ level } & NS & $<0.001$ & $<0.001$ & $<0.001$ & NS & $<0.05$ \\
\hline & $\begin{array}{l}\text { Fasting } \\
\text { insulin }\end{array}$ & $\begin{array}{l}\text { Fasting } \\
\text { FFA }\end{array}$ & $\begin{array}{l}\text { Glucose } \\
120 \mathrm{~min}\end{array}$ & $\begin{array}{l}\text { Lactate } \\
120 \mathrm{~min}\end{array}$ & $\begin{array}{l}\text { Insulin } \\
120 \mathrm{~min}\end{array}$ & $\begin{array}{c}\text { FFA } \\
120 \mathrm{~min}\end{array}$ \\
\hline & mU/liter & $\mu M$ & $m M$ & $\mu M$ & mU/liter & $\mu M$ \\
\hline Lean & $5 \pm 1$ & $494 \pm 68$ & $7.2 \pm 0.4$ & $924 \pm 59$ & $30 \pm 5$ & $52 \pm 13$ \\
\hline Obese & $18 \pm 6$ & $696 \pm 53$ & $7.0 \pm 0.4$ & $1060 \pm 77$ & $101 \pm 20$ & $143 \pm 46$ \\
\hline$P$ level & $<0.05$ & $<0.01$ & NS & NS & $<0.001$ & $<0.01$ \\
\hline
\end{tabular}

Glucose, insulin, FFA, and lactate levels were measured in the postabsorptive state and 120 min after oral ingestion of $100 \mathrm{~g}$ of glucose. Abbreviation: WHR, waist/hip circumference ratio.

Microdialysis procedures. Microdialysis catheters $(30 \times 0.3-\mathrm{mm}$ Cuprophan B4 AH, 3,000-mol wt cutoff; Cobe, Denver, CO) were placed in the right abdominal subcutaneous tissue, $5 \mathrm{~cm}$ lateral to the umbilicus, and in the left femoral subcutaneous tissue, one third of the distance between the patella and the superior anterior iliac spine. The nylon tubing inlet of the microdialysis catheter was connected to a microinjection pump (CMA Microdialysis, Stockholm, Sweden) and saline with $2.5 \mathrm{mM}$ glucose added (18) perfused the system at a rate of $2.5 \mu \mathrm{l} / \mathrm{min}$. Addition of $2.5 \mathrm{mM}$ glucose to the perfusion fluid prevents drainage of glucose from the tissue and maintains the tissue glucose concentration (interstitial glucose has been shown to equal plasma glucose ) (18). After 60 min of equilibration, the dialysate was collected in 10-min intervals from the outlet of the tubing. A maximum delay of 12 min is expected between an ongoing change in the surrounding extracellular fluid and the dialysate for lactate when samples are collected every $10 \mathrm{~min}(6)$.

The calibration procedure has previously been described in detail (18). Briefly, five different concentrations of lactate $(0-1,000 \mu \mathrm{M})$ were added to the perfusate and the net change of lactate concentration recorded in the dialysate $\left(\right.$ lactate $_{\text {out }}-$ lactate $_{\text {in }}=$ net change). Regression analysis was used to calculate the perfusate lactate concentration resulting in no net change in dialysate lactate content (equal to interstitial lactate concentration) and the proportion of interstitial lactate recovered in the dialysate. During the calibration period which persisted for $\sim 5 \mathrm{~h}$ there was a good linear correlation between lactate concentration in the perfusate and net change in the dialysate $(r<-0.9)$. Mean recovery of interstitial lactate in the dialysate was $39 \pm 2 \%$ ( $n$ $=36$ ).

Around 1 p.m. each subject ingested $100 \mathrm{~g}$ of glucose dissolved in $\sim 250 \mathrm{ml}$ of lemon-flavored tap water. Blood samples were drawn just before the glucose load and lactate levels in the subcutaneous tissue and arterialized venous plasma were followed for $120 \mathrm{~min}$. The samples were kept on ice and immediately centrifuged $\left(3,000 \mathrm{~g},+4^{\circ} \mathrm{C}\right)$. Blood plasma and dialysates were collected and stored at $-20^{\circ} \mathrm{C}$ until analyzed.

Each study was terminated by aspirating fat biopsies in local anaesthesia (Carbocain, Astra, Södertälje, Sweden) from the microdialysis sites. Mean fat cell size and fat cell number per kilogram of adipose tissue were estimated (19). Body fat mass was estimated by measuring the bioelectrical impedance (BIA-103, RJL Systems Inc., Detroit, MI) (20).

A previous investigation indicates that skin is a significant source of lactate (21). Because metabolites formed in skin and subcutaneous adipose tissue may be diluted in the same intercellular water space, control experiments were performed to evaluate whether lactate levels measured in the subcutaneous tissue with microdialysis may be influenced by skin lactate release. In these experiments, four obese (age
$32 \pm 2 \mathrm{yr}$, body mass index [BMI $]^{1} 40.2 \pm 1.9 \mathrm{~kg} / \mathrm{m}^{2}$ ) and four lean (age $30 \pm 1 \mathrm{yr}$, BMI $21.9 \pm 1.2 \mathrm{~kg} / \mathrm{m}^{2}$ ) male volunteers participated. Each subject was investigated with three microdialysis catheters placed in the abdominal region at three different tissue levels: in the skin, at $\sim 5$ $\mathrm{mm}$, and $\sim 10 \mathrm{~mm}$ deep in the subcutaneous tissue, respectively. Each catheter was calibrated for $5 \mathrm{~h}$ and the interstitial lactate and glycerol concentrations calculated for each tissue level. As shown in Fig. 1, the lactate levels were higher and the glycerol levels lower in the skin as compared with subcutaneous tissue in both subject groups, indicating significant lactate release and less glycerol formation in the former tissue. However, the lactate concentrations were not different in deep as compared to superficial subcutaneous interstitial fluid indicating no further "contamination" by skin lactate at this level. Thus, the data show that interstitial lactate measured at 5-mm tissue depth or deeper originates from the subcutaneous tissue both in lean and obese subjects. All experiments shown in the Results were performed with microdialysis catheters placed at least at this tissue depth.

Blood flow measurements. Adipose tissue blood flow (ATBF) was measured before and for $120 \mathrm{~min}$ after the oral glucose tolerance test (OGTT) by the ${ }^{133} \mathrm{Xe}$-clearance method (22). Briefly, 6-9 MBq of ${ }^{133} \mathrm{Xe}$ (Mallinckrodt, Petten, The Netherlands) in $0.1 \mathrm{ml}$ of sterile saline was injected into the subcutaneous adipose tissue contralateral to the microdialyzing sites and at least $5 \mathrm{~mm}$ under the skin. After $60 \mathrm{~min}$, clearance of ${ }^{133} \mathrm{Xe}$ was monitored continuously with a $2 \times 2$-in. $\mathrm{NaI}$ (TI) detector (Canberra Industries Inc., Meriden, CT) covered by a cylindrical collimator and coupled to a multichannel analyzer (ND 62, Nuclear Data Instrumentation, Schaumburg, IL). In order not to interfere with the counting geometry the detector was placed $30-50 \mathrm{~cm}$ from the ${ }^{133} \mathrm{Xe}$ depot. Only an energy interval corresponding to the photopeak of $81 \mathrm{keV}$ was registered and the initial counting rate ranged from $5 \times 10^{4}$ to $10^{5} \mathrm{cpm}$ enabling reliable measurements for at least 3-4 h. Counts were accumulated during consecutive 60 -s intervals and plotted on a logarithmic-linear diagram as a function of time. Subcutaneous adipose tissue blood flow was then calculated according to the formula: $A T B F=k \times \lambda \times 100(\mathrm{ml} / 100 \mathrm{~g} / \mathrm{min})$, where $\lambda$ is the tissue to blood partition coefficient for ${ }^{133} \mathrm{Xe}$ at equilibrium, and $k$ is the rate constant of the washout curve. Experimental values of $k$ were estimated as: $\left(\ln y_{1}-\ln y_{2}\right) \times T^{-1}$ where $y_{1}$ and $y_{2}$ are the counting rates at two occasions ( $>25$-min interval) and $T$ is time in minutes between these registrations. A mean value of $10.0 \mathrm{ml} / \mathrm{g}$ was used for the partition coefficient (22). Control experiments in our laboratory have shown that the partition coefficient estimated by measuring the triglyceride content in fat biopsies is similar in adipose tissue from lean and

1. Abbreviations used in this paper: ATBF, adipose tissue blood flow; BMI, body mass index; OGTT, oral glucose tolerance test. 


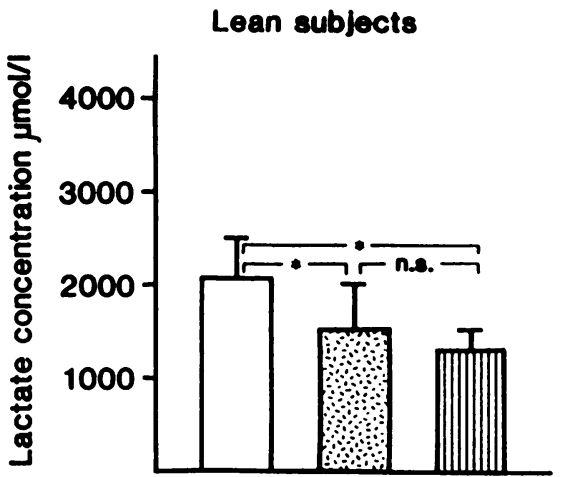

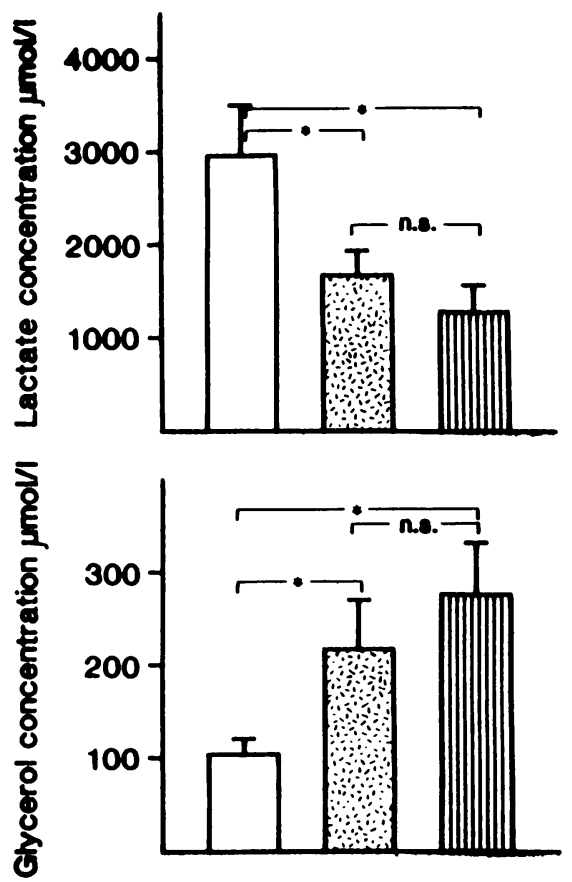

Obese subjects
Figure 1. Interstitial lactate and glycerol concentration estimated in three different tissue layers in four lean and four obese subjects. Microdialysis was performed concomitantly in catheters placed close to the epidermis and either superficially or deeply in the subcutaneous adipose tissue. Key: ( $\square$ ) intracutaneous; ( $\square$ ) superficial subcutaneous; (圆) deep subcutaneous; data are means \pm SE. ${ }^{*} P<0.05$, n.s., not significant. obese subjects (P.-A. Jansson, manuscript to be published). In other control experiments, the mean relative error of ${ }^{133} \mathrm{Xe}$ clearance measured at two corresponding abdominal subcutaneous sites was $\sim 24 \%$ ( $n=20)$, confirming previous studies (22).

Chemical analyses. Lactate levels were analyzed according to Loomis (23). Glucose and FFA levels were estimated enzymatically. Insulin was analyzed with a radioimmunoassay (Pharmacia, Uppsala, Sweden).

Estimation of lactate release. According to Fick's principle, arterialized venous plasma $(A)$ and capillary venous plasma concentrations of lactate $(V)$ and plasma flow rate $(Q)$ were entered into the formula: ( $V$ $-A) \times Q \times\left(1-\right.$ hematocrit $\left.\times 10^{-2}\right)(\mu \mathrm{mol} / 100 \mathrm{~g} \cdot \mathrm{min})$. Conversion of interstitial $(I)$ to venous $(V)$ lactate levels was performed by the equation: $V=I-A \times\left(1-e^{-P S / Q}\right)+A$, where $P S$ is the permeability surface product area (adopted to be $\sim 5 \mathrm{ml} / 100 \mathrm{~g} \cdot \min$ for lactate) $(24,25)$.

Statistical analyses. Regression analyses were performed with the least squares method and linear correlations were tested using Pearson's correlation coefficient. Student's two-tailed $t$ test was used for paired and unpaired data. The Wilcoxon signed rank test was applied for paired comparisons of blood flow, tissue levels, and lactate release.

\section{Results}

Measurements in the postabsorptive state. In the fasting state, the mean blood glucose level was similar in the two subject groups, whereas the mean plasma insulin, FFA, and lactate levels were significantly increased in the obese group (Table I). Mean body fat mass was $11 \pm 1$ and $48 \pm 6 \mathrm{~kg}($ mean $\pm \mathrm{SE})(P$ $<0.001$ ) in the lean and obese group, respectively (Table I). Mean fat cell size was increased in the femoral compared to the abdominal site $(P<0.05)$ in the lean subjects. The fat cells were larger in both regions in the obese when compared to the lean group (Table II).

Fig. 2 shows the lactate levels in arterialized plasma and interstitial fluid, as well as plasma glucose, in both groups before and after oral ingestion of glucose. In the postabsorptive state, plasma lactate was significantly increased in the obese subjects, whereas interstitial lactate in the two regions was similar in both groups (Fig. 2). Plasma lactate correlated positively with BMI $(r=0.628, P<0.01, n=18)$. The difference between interstitial and plasma lactate was similar for both groups and the two tissue regions (Fig. 3). Also, no significant regional differences were recorded in either group in the postabsorptive state.

Postabsorptive ATBF (Table III) was significantly lower in the obese subjects in the abdominal region but not in the femoral region. Furthermore, in the abdominal region but not in the femoral region. Furthermore, in the abdominal region there was a significant negative correlation between fat cell size and ATBF $(r-0.498, P<0.05, n=18)$.

Table II. Mean Fat Cell Sizes of the Subcutaneous Regions in the Lean and Obese Individuals

\begin{tabular}{|c|c|c|c|c|c|c|}
\hline & \multicolumn{2}{|c|}{ Cell size } & \multirow[b]{2}{*}{$P$ level } & \multicolumn{2}{|c|}{ Cell weight } & \multirow[b]{2}{*}{$P$ level } \\
\hline & Abdominal & Femoral & & Abdominal & Femoral & \\
\hline & \multicolumn{2}{|c|}{$\mu m$} & \multicolumn{4}{|c|}{$(\mu g / c e l l)$} \\
\hline Lean & $83 \pm 3$ & $93 \pm 3$ & $<0.05$ & $0.31 \pm 0.04$ & $0.45 \pm 0.04$ & $<0.05$ \\
\hline Obese & $108 \pm 3$ & $111 \pm 4$ & NS & $0.68 \pm 0.05$ & $0.71 \pm 0.05$ & NS \\
\hline$P$ level & $<0.001$ & $<0.05$ & & $<0.001$ & $<0.05$ & \\
\hline
\end{tabular}



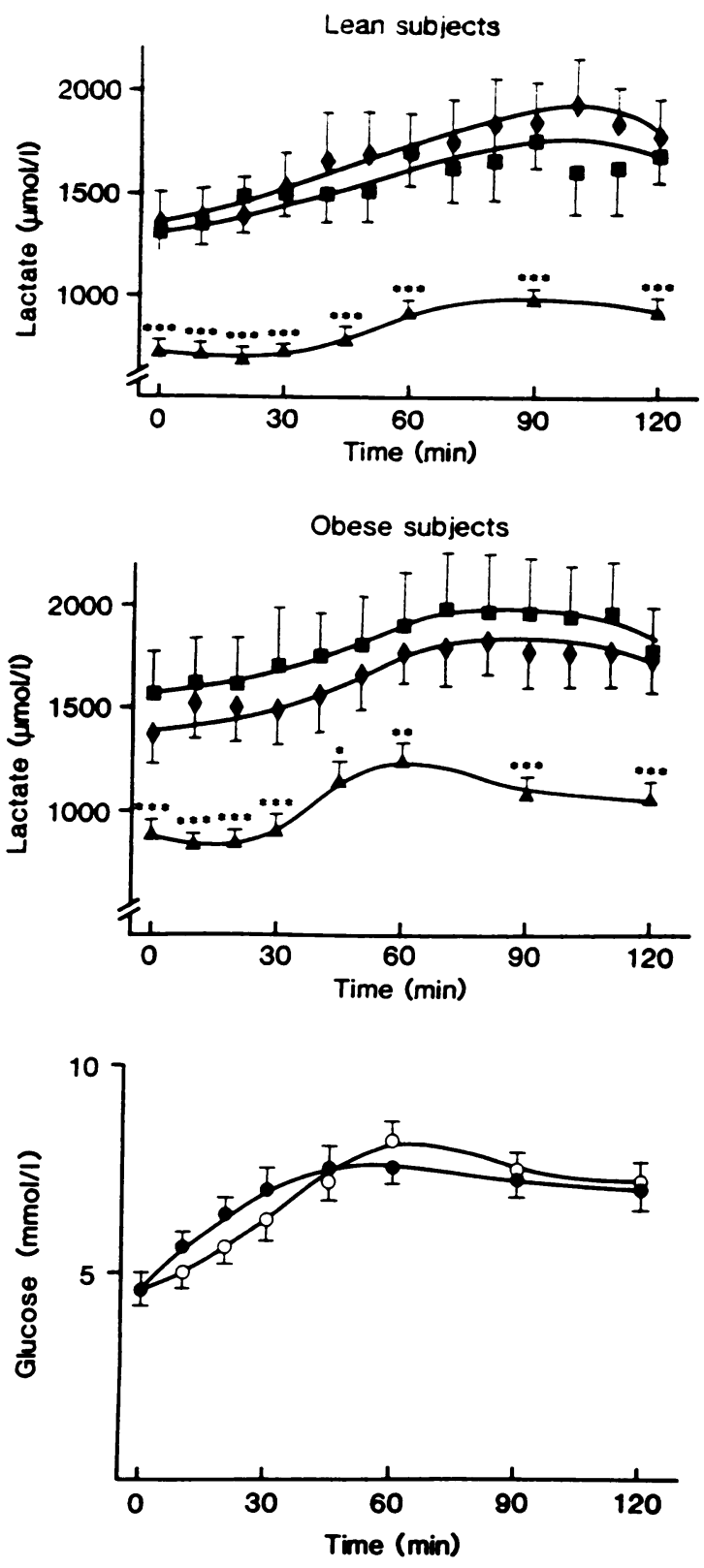

Figure 2. Plasma and interstitial lactate levels in the abdominal and femoral regions after an overnight's fast and $2 \mathrm{~h}$ after oral ingestion of $100 \mathrm{~g}$ of glucose. Bottom panel shows plasma glucose in $(\mathrm{O})$ lean and $(\bullet)$ obese subjects. Key: $(\bullet)$ abdominal interstitial lactate: $(\bullet)$ Femoral interstitial lactate; ( $\Delta$ ) Plasma lactate; data are Means \pm SE. ${ }^{*} P<0.05$ or ${ }^{* *} P<0.01$ or ${ }^{* * *} P<0.001$ compared to interstitial lactate concentrations.

Fig. 4 shows the apparent lactate release per kilogram subcutaneous tissue and minute. In the postabsorptive state, no regional differences were seen in either subject group. Furthermore, apparent lactate release per unit tissue weight was similar in both groups. When the data were calculated per cell, however, apparent lactate release was significantly higher in the obese subjects in the femoral region (Table IV). A positive correlation between fat cell size and cellular lactate release was also present in this region $(r 0.593, P<0.05)$.

Measurements after $O G T T$. After ingestion of $100 \mathrm{~g}$ of glucose an increase in interstitial lactate was seen after 30-40 min
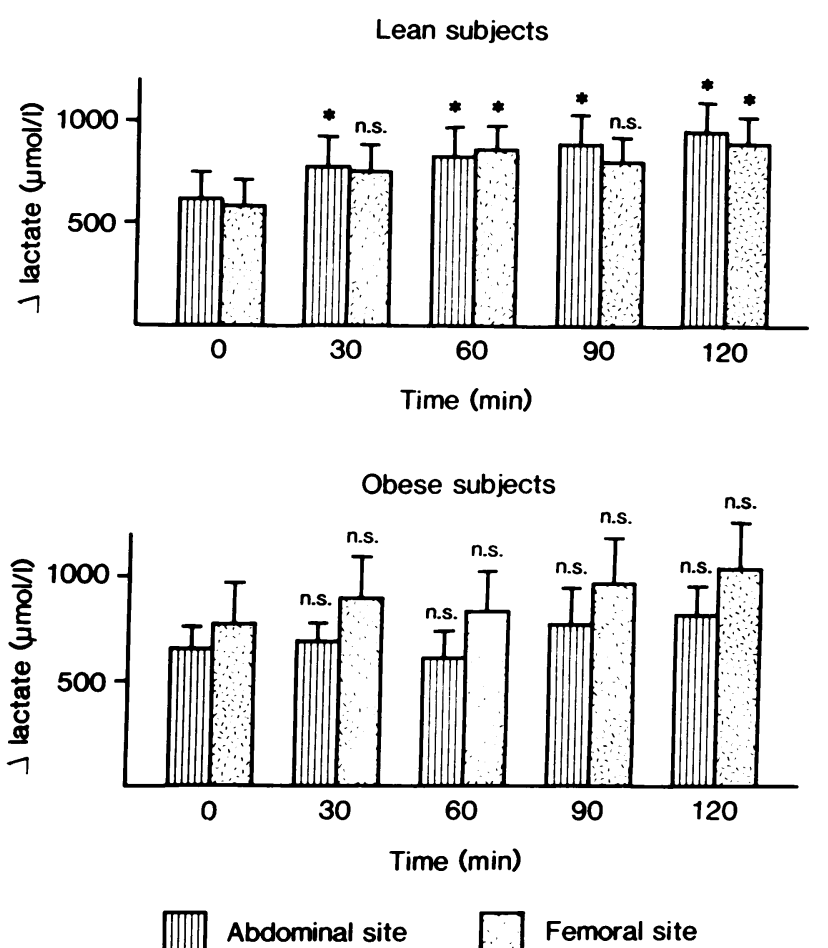

Figure 3. Interstitial-arterial differences in lactate levels ( $\Delta$ lactate) in the fasting state and for $2 \mathrm{~h}$ after oral ingestion of $100 \mathrm{~g}$ of glucose. Key is above. Data are means \pm SE. ${ }^{*} P<0.05$ as compared to time zero. n.s., not significant.

$(P<0.05)$ in both groups reaching a maximum concentration after 80-90 min (Fig. 2). No regional differences were seen in either group. Moreover, interstitial lactate was higher than in plasma in both groups following the OGTT (Fig. 2). The rise in plasma lactate after oral glucose was more rapid in the obese compared to the lean group ( $45 \mathrm{~min} P<0.01$, and $60 \mathrm{~min} P$ $<0.01$, respectively). Furthermore, plasma lactate was higher after $45 \mathrm{~min}(P<0.05)$ and $60 \mathrm{~min}(P<0.05)$ in the obese than in the lean group (Fig. 2), whereas the net maximal increase in plasma lactate after oral glucose was similar in the two subject groups.

Fig. 3 shows the interstitial-arterial lactate concentration differences ( $\triangle$ lactate $)$ in the postabsorptive state and after oral glucose. No regional differences were seen. However, $\Delta$ lactate increased after glucose ingestion in both regions in the lean group, whereas this was not seen in the obese subjects (Fig. 3 ).

In the lean subjects there was an increase in ATBF in both regions for up to $120 \mathrm{~min}$ after the OGTT, whereas the blood flow response to glucose was blunted in the obese (Table III). In lean subjects, apparent subcutaneous lactate release per $\mathrm{kg}$ tissue (Fig. 4) 120 min after oral glucose was significantly increased $51 \pm 13 \%$ and $48 \pm 12 \%$ in the abdominal $(P<0.05)$ and femoral $(P<0.05)$ regions, respectively. However, in the obese subjects no such increase was seen in either tissue region.

\section{Discussion}

Postabsorptive state. In the postabsorptive state, interstitial lactate levels in the subcutaneous adipose tissue were clearly higher than in plasma indicating local release of lactate. Similar lactate concentrations in the interstitial water were found in 
Table III. ATBF before (0 min) and up to 120 min after an OGTT in Lean and Obese Subjects

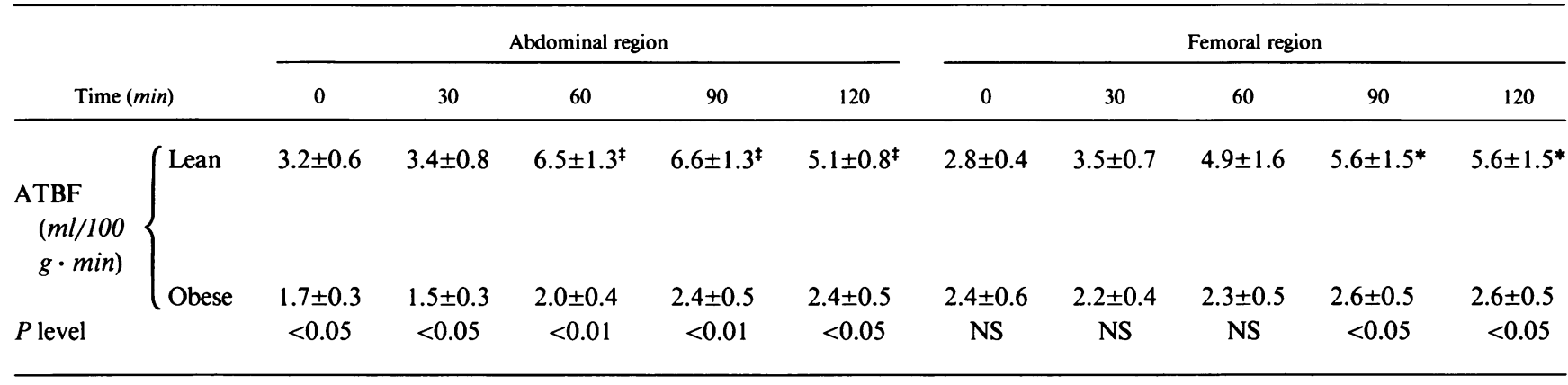

Data are means \pm SE. ${ }^{*} P<0.05$ and ${ }^{\ddagger} P<0.001$ compared to time zero. Comparisons between groups are also shown.

lean subjects in a previous study from our laboratory (6). However, considerably lower interstitial (7) or local venous (5) levels have been reported from other groups using other methods. In a microdialysis study by Hagström et al. (7), the use of a different microdialysis probe, a higher perfusion rate and perfusion with medium without added glucose may explain the difference in interstitial lactate concentration. In a previous study was shown that microdialysis may deplete tissue glucose if a maximal concentration gradient of glucose is created over the dialysis membrane and that this may result in reduced lactate release (6).

Frayn et al. (5) reported low lactate levels in plasma from a superficial abdominal vein, draining both skin and subcutaneous tissue, and low rates of lactate release in the postabsorptive state. However, the higher lactate levels obtained in the present study were measured directly in the subcutaneous tissue and are probably more representative for the adipose tissue. It is unlikely that the microdialysis catheter induced ischemic conditions in the ambient tissue since previous studies have shown that the interstitial adenosine concentration is low (26) and the pyruvate level high (7). Furthermore, direct measurements of $\mathrm{PO}_{2}$ in the microdialysate collected with a device identical to

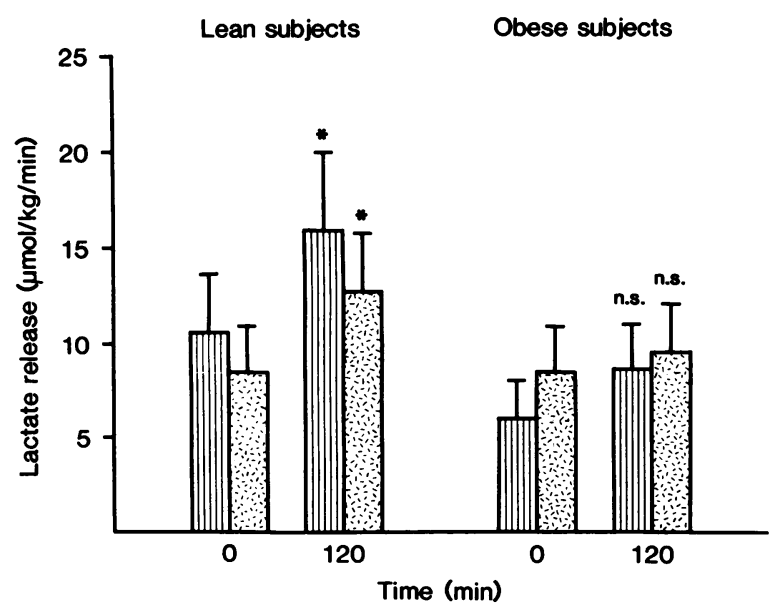

Abdominal site Femoral site

Figure 4. Apparent lactate release in the postabsorptive state in abdominal and femoral subcutaneous adipose tissue before and 120 min after the OGTT. Key is above. Data are means \pm SE. ${ }^{*} P<0.05$ as compared to time zero. n.s., not significant. that presently used have shown a high oxygen tension in the interstitial fluid ambient to the catheter (27).

Precise calculation of local apparent lactate release is hampered by the variability in the tissue concentrations and variation in adipose tissue blood flow. However, by using the presently employed in situ microdialysis calibration technique and long-term recordings of ${ }^{133} \mathrm{Xe}$ clearance, local adipose tissue glycerol release could be estimated with acceptable precision (15). Since apparent lactate release was only measured in subcutaneous adipose tissue regions the present data do not allow us to safely quantitate the role of the total adipose tissue for whole body lactate production.

The calculated apparent lactate release in the subcutaneous tissue could theoretically be influenced by skin lactate formation (Fig. 1). However, the finding of a constant lactate concentration even deep in the adipose tissue, whereas the glycerol concentration is low in the skin, indicates that the adipose tissue produces lactate and that the diffusion rate of small molecular compounds between the skin and subcutaneous tissue is limited. Furthermore, the data shown in Fig. 1 indicate that there is no difference between lean and obese subjects in this regard.

Taken together, it can be concluded that subcutaneous adipose tissue produces considerable amounts of lactate in the postabsorptive state. For reasons discussed above, the present study does not allow an exact estimation of the importance of this tissue for total body lactate appearance. However, studies using turnover measurements have estimated total daily body lactate appearance to $\sim 1,350 \mathrm{mmol} / 24 \mathrm{~h}$ in normal man (28). Provided that visceral fat is at least as efficient as the subcutaneous fat in producing lactate, the present data suggest that even the normal body fat mass in lean subjects $(\sim 10 \mathrm{~kg})$ contributes significantly to total body lactate production in the

Table IV. Mean Apparent Lactate Release per Fat Cell in Two Subcutaneous Regions in Lean and Obese Subjects in the Postabsorptive State

\begin{tabular}{|c|c|c|c|}
\hline & $\begin{array}{l}\text { Abdominal } \\
\text { region }\end{array}$ & $\begin{array}{l}\text { Femoral } \\
\text { region }\end{array}$ & $P$ level \\
\hline \multicolumn{4}{|c|}{$\mathrm{fmol} / \mathrm{min}$} \\
\hline Lean & $3.5 \pm 0.6$ & $3.5 \pm 0.7$ & NS \\
\hline Obese & $4.4 \pm 1.3$ & $8.6 \pm 2.2$ & NS \\
\hline$P$ level & NS & $<0.05$ & \\
\hline
\end{tabular}


postabsorptive state. Studies with isolated adipocytes in vitro have suggested that visceral fat cells are even more effective in producing lactate than subcutaneous cells (29).

In the obese, plasma lactate was significantly higher than in lean subjects (Table I), confirming previous observations by Lovejoy et al. (9). The high interstitial lactate levels in the adipose tissue again indicate a significant local lactate release (Fig. 2). Net apparent lactate release per $\mathrm{kg}$ adipose tissue was similar to that in lean subjects. Since fat cell size was increased in the obese subjects (Table II), lactate release per cell was also significantly increased in the obese ("Femoral region" in Table IV). This is in agreement with the previous finding that large adipose cells form more lactate than small adipocytes (2).

The finding that the apparent lactate release per kilogram of subcutaneous tissue is similar in lean and obese subjects suggests an important role of the adipose tissue mass for total body lactate formation. Furthermore, since lactate is considered as the major gluconeogenic precursor, lactate release from the expanded adipose tissue in obese subjects may contribute to the impaired ability of insulin to inhibit hepatic glucose production (30) as well as enhancing hepatic lipid synthesis.

A fter OGTT. After an oral glucose load, interstitial lactate levels increased in parallel with the plasma lactate. However, in the lean subjects a significant increase of the interstitial-arterial lactate concentration difference was seen. This confirms previous observations of an increased lactate formation in the adipose tissue after glucose ingestion (5-7). In the lean subjects, mean apparent lactate release by the adipose tissue was calculated to increase $\sim 50 \% 120$ min after oral glucose without any obvious regional differences. These data suggest that even if the maximal lactate release, estimated at $120 \mathrm{~min}$ after the OGTT, persisted for $4 \mathrm{~h}$ and visceral fat is twice as efficient in lactate release, total body fat could not convert more than $2-3 \%$ of the ingested glucose to lactate. This confirms the previous suggestion based on studies of adipose tissue fragments in vitro (14) and of venous plasma from the abdominal wall (31) that the adipose tissue is of minor importance for glucose homeostasis in the postprandial state. Interestingly, in vitro studies with isolated human adipocytes show that $50-70 \%$ of the glucose uptake results in lactate formation indicating that as much as $10 \%$ of ingested glucose theoretically could be metabolized in the adipose tissue and released as lactate $(3,32)$. However, the present study indicates that this high capacity to form lactate only occurs under in vitro conditions.

In the obese subjects, the lactate concentration increased significantly both in plasma (where net increase was similar to that in lean subjects) and in the interstitial fluid after glucose ingestion. However, the interstitial-arterial lactate gradient was not significantly increased and, furthermore, adipose tissue blood flow remained unchanged. Consequently, the apparent rate of subcutaneous lactate release was not increased, indicating an insulin-resistant state in the adipose tissue. These data are in agreement with results from previous measurements in plasma where excessive lactate production in insulin-resistant subjects was found to mainly occur in the postabsorptive state (9). Furthermore, the present data indicate that in both lean and obese subjects body fat mass only significantly contributes to total lactate release in the postabsorptive state, whereas other tissues are more important sources of lactate release in the postprandial state.

ATBF in the abdominal subcutaneous region was lower in the obese when compared to the lean subjects. These data are in agreement with those reported by Larsen et al. (22) and further support the concept that ATBF decreases with an increased adipose tissue thickness. Moreover, the finding that ATBF correlates negatively with fat cell size and that blood flow per cell is constant $\left(\sim 1.4 \pm 0.4 \mathrm{ml} / 10^{9}\right.$ cells $\left.\cdot \min \right)$ irrespective of cell size, confirms previous data from different fat depots in the dog (33). The blunted increase in ATBF in obesity after an oral glucose load was also found in our recent study (15) and an impaired increase in skeletal muscle blood flow during a hyperinsulinemic clamp in obese subjects has also been reported (34). The mechanism(s) for this difference between lean and obese, insulin-resistant individuals remains to be clarified.

In summary, the present data show that the subcutaneous fat is a significant source of lactate in the postabsorptive state. Furthermore, obese subjects have a greater apparent lactate release than lean individuals since lactate release is proportional to the adipose tissue mass.

\section{Acknowledgments}

The technical assistance by Helle Persson and Vibeke Malmros is gratefully acknowledged. The authors want to thank Dr. Tom William-Olsson and Professor Lars Sjöström for help in recruiting the obese patients and Dr. Henning von Schenck for performing the insulin analyses. Excellent secretarial aid was provided by Gudrun Jonson.

This study was supported by grants from the Swedish Medical Research Council (B-3506), the Faculty of Medicine at the University of Göteborg, Nordisk Insulinfond, Swedish Hoechst, the Swedish Diabetes Association, Svenska Sällskapet för Medicinsk forskning, the Swedish Society of Medicine, Göteborgs Läkaresällskap, the Royal Society of Arts and Sciences in Gothenburg and "Förenade Liv" Mutual Group Life Insurance Company, Stockholm, Sweden.

\section{References}

1. Kreisberg, R. A. 1972. Glucose-lactate interrelations in man. N. Engl. J. Med. 287:132-137.

2. Crandall, D. L., S. K. Fried, A. A. Francendese, M. Nickel, and M. DiGirolamo. 1983. Lactate released from isolated rat adipocytes: influence of cell size, glucose concentration, insulin and epinephrine. Horm. Metab. Res. 15:326-329.

3. Kashiwagi, A., M. A. Verso, J. Andrews, G. Vasques, G. Reaven, and J. E. Foley. 1983. In vitro insulin resistance of human adipocytes isolated from subjects with noninsulin-dependent diabetes mellitus. J. Clin. Invest. 72:1246-1254.

4. Fredholm, B. B. 1974. Vascular and metabolic effects of theophylline dibuturyl-cyclic AMP and dibuturyl cyclic GMP in canine subcutaneous adipose tissue in situ. Acta Physiol. Scand. 90:226-236.

5. Frayn, K. N., S. W. Coppack, S. M. Humphreys, and P. L. Whyte. 1989. Metabolic characteristics of human adipose tissue in vivo. Clin. Sci. 76:509-516.

6. Jansson, P.-A., U. Smith, and P. Lönnroth. 1990. Evidence for lactate production by human adipose tissue in vivo. Diabetologia. 33:253-256.

7. Hagström, E., P. Arner, U. Ungerstedt, and J. Bolinder. 1990. Subcutaneous adipose tissue: a source of lactate production after glucose ingestion in humans. Am. J. Physiol. 258:E888-E893.

8. Consoli, A., N. Nurjhan, J. J. Reilly, D. M. Bier, and J. Gerich. 1990. Mechanism of increased gluconeogenesis in noninsulin-dependent diabetes mellitus: role of alterations in systemic, hepatic, and muscle lactate and alanine metabolism. J. Clin. Invest. 86:2038-2045.

9. Lovejoy, J., B. Mellen, and M. DiGirolamo. 1990. Lactate generation following glucose ingestion: relation to obesity, carbohydrate tolerance and insulin sensitivity. Int. J. Obesity. 14:843-855.

10. Doar, J. W. H., and D. G. Cramp. 1970. The effects of obesity and maturity-onset diabetes mellitus on L (+) lactic acid metabolism. Clin. Sci. 76:509516.

11. Andersen, T., P. McNair, N. Fogh-Andersen, T. T. Nielsen, L. Hyldstrup, and I. Transbol. 1986. Increased para-thyroid hormone as a consequence of changed complex binding of plasma calcium in morbid obesity. Metab. Clin. Exp. 35:147-151.

12. Consoli, A., N. Nurjhan, F. Capani, and J. Gerich. 1989. Predominant role of gluconeogenesis in increased hepatic glucose production in NIDDM. Diabetes. 38:550-557. 
13. Lovejoy, J., F. D. Newby, S. S. P. Gebhart, and M. DiGirolamo. 1992 Insulin resistance in obesity is associated with elevated basal lactate levels and diminished lactate appearance following intravenous glucose and insulin. Metab Clin. Exp. 41:22-27.

14. Björntorp, P., and L. Sjöström. 1978. Carbohydrate storage in man: speculations and some quantitative considerations. Metab. Clin. Exp. 27:1853-1865.

15. Jansson, P.-A., A. Larsson, U. Smith, and P. Lönnroth. 1992. Glycerol production in subcutaneous adipose tissue in lean and obese man. J. Clin. Invest. 89:1610-1617.

16. National Diabetes Data Group. 1979. Classification and diagnosis of diabetes mellitus and other categories of glucose intolerance. Diabetes. 28:10391057.

17. Attvall, S., J. Fowelin, H. von Schenck, U. Smith, and I. Lager. 1992. Insulin-antagonistic effects of pulsatile and continuous glucagon infusions in man: a comparison with the effect of adrenaline. J. Clin. Endocrinol. Metab. 74:1110-1115

18. Lönnroth, P., P.-A. Jansson, and U. Smith. 1987. A microdialysis method allowing characterization of intercellular water space in humans. Am. J. Physiol 253:E228-E231.

19. Smith, U., L. Sjöström, and P. Björntorp. 1972. Comparison of two meth ods for determining human adipose cell size. J. Lipid. Res. 13:822-824.

20. Lukaski, H. C., W. W. Bolonchuk, C. B. Hall, and W. A. Siders. 1986. Validation of a tetrapolar bioelectrical impedance method to assess human body composition. J. Appl. Physiol. 60:1327-1332.

21. Johnson, J. A., and R. M. Fusaro. 1972. The role of skin in carbohydrate metabolism. Adv. Metab. Dis. 6:1-55.

22. Larsen, O. A., N. A. Lassen, and F. Quaade. 1966. Blood flow through human adipose tissue determined with radioactive Xenon. Acta Physiol. Scand. 66:337-345.

23. Loomis, M. E. 1961. An enzymatic fluorometric method for the determination of lactic acid in serum. J. Lab. Clin. Med. 57:966-969.
24. Lassen, N. A. 1967. Capillary diffusion capacity of sodium studied by the clearances of $\mathrm{Na}-24$ and $\mathrm{Xe}-133$ from hyperemic skeletal muscle in man. Scand. J. Clin. Lab. Invest. 19: (Suppl. 99) 24-26.

25. Paaske, W. P. 1977. Absence of restricted diffusion in adipose tissue capillaries. Acta Physiol. Scand. 100:430-436.

26. Lönnroth, P., P.-A. Jansson, B. B. Fredholm, and U. Smith. 1989. Microdialysis of intercellular adenosine concentration in subcutaneous tissue in humans. Am. J. Physiol. 256:E250-E255.

27. Bülow, J., and L. Simonsen. 1992. Simultaneous measurements of local metabolite concentrations and gas tensions in subcutaneous tissue by microdialysis in vivo. Acta Physiol. Scand. 146:608a. (Abstr.)

28. Buchalter, S. E., M. R. Crain, and R. Kreisberg. 1989. Regulation of lactate metabolism in vivo. Diabetes Metab. Rev. 5:379-391.

29. Newby, F. D., M. N. Sykes, and M. DiGirolamo. 1988. Regional differences in adipocyte lactate production from glucose. Am. J. Physiol. 255:E716E722.

30. Kolterman, O. G., J. Insel, M. Saekow, and J. M. Olefsky. 1980. Mechanisms of insulin resistance in human obesity: evidence for receptor and postreceptor defects. J. Clin. Invest. 65:1272-1284.

31. Coppack, S. W., R. M. Fisher, G. F. Gibbons, S. M. Humphreys, M. J. McDonough, J. L. Potts, and K. N. Frayn. 1990. Postprandial substrate deposition in human forearm and adipose tissue in vivo. Clin. Sci. 79:339-348.

32. Mårin, P., M. Rebuffé-Scrive, U. Smith, and P. Björntorp. 1987. Glucose uptake in human adipose tissue. Metab. Clin. Exp. 36:1154-1160.

33. DiGirolamo, M., N. S. Skinner, H. G. Hanley, and G. Sachs. 1971. Relationship of adipose tissue blood flow to fat cell size and number. Am. J. Physiol. 220:932-937.

34. Laakso, M., S. V. Edelman, G. Brechtel, and A. D. Baron. 1990. Decreased effect of insulin to stimulate skeletal muscle blood flow in obese man. $J$. Clin. Invest. 85:1844-1852. 